\title{
FACTORS AFFECTING BMI
}

\section{Assessment of the effect of sociodemographic factors on BMI In the population of Ghulam Mohammad Abad Faisalabad.}

Dr. Abdul Sattar, Dr. Shahbaz Baig, Dr. Naveed ur Rehman, Dr. Badar Bashir

ABSTRACT... Objective: To examine the effect of different sociodemographic factors on the BMI. Study Design: Descriptive Cross Sectional Study. Place and Duration of Study: People of Ghulam Mohammadabad and Marzi Pura attending OPD at Independent University Hospital Ghulam Mohammadabad and Marzi Pura Faisalabad. One Month of duration extending from July to August 2012. Patients and Methods: 493 respondents were selected by convenient sampling. A semi structured questionnaire was used to collect the information from the sample. First of all, an informed consent was obtained from the respondents under study and secrecy of the information was ensured. By data analysis through SPSS Version 17, frequency tables were prepared. Results: The result of this study shows that BMI is less than 18.5 in $25.4 \%$ of the males as compared to $11.5 \%$ in females. $22.9 \%$ married persons were having BMI above 30 as compared to 6.6 percent unmarried. This study also shows $21.1 \%$ of the smokers were having BMl above 30 as compared to $18.3 \%$ in non smokers. Similarly $18.2 \%$ of the respondents sleeping less than 10 hours per day were having BMI above 30 as compare to $15.4 \%$ sleeping more than 10 hours per day. Result also shows $25.8 \%$ diabetics having 18.5 to $24 \mathrm{BMI}$ while $21.5 \%$ in non diabetics. There was family history of obesity in $22.4 \%$ only. Conclusions: Males are more underweight as compared to females and that females are always on higher side of BMI. Married persons were more obese as compared to unmarried. Per month income, background history of diabetes mellitus and family history of obesity found to have a profound effect on BMI.

Key words: BMI, Diabetes Mellitus, Physical Exercise, Sleeping, Background.

\section{Article Citation}

Sattar A, Baig S, Naveed ur Rehman, Bashir B. Factors affecting BMl; Assessment of the effect of sociodemographic factors on BMI In the population of Ghulam Mohammad Abad Faisalabad. Professional Med J 2013;20(6): 956-964.

\section{INTRODUCTION}

Body Mass Index (BMI) is a number calculated from a person's weight and height. BMI is a fairly reliable indicator of body fatness for most people. BMI does not measure body fat directly, but research has shown that BMI correlates to direct measures of body fat, such as underwater weighing and dual energy $x$-ray absorptiometry (DXA). ${ }^{1,2}$ BMI can be considered an alternative for direct measures of body fat. Additionally, BMI is an inexpensive and easy-toperform method of screening for weight categories that may lead to health problems ${ }^{1}$.

$\mathrm{BMI}$ is used as a screening tool to identify possible weight problems for adults. However, BMI is not a diagnostic tool. For example, a person may have a high BMI. However, to determine if excess weight is a health risk, a healthcare provider would need to perform further assessments. These assessments might include skin fold thickness measurements, evaluations of diet, physical activity, family history, and other appropriate health screenings.

$\mathrm{BMI}$ is calculated the same way for both adults and children. The calculation is based on the following formulae:

\begin{tabular}{|c|c|}
\hline Measurement Units & Formula and Calculation \\
\hline $\begin{array}{l}\text { Kilograms and meters } \\
\text { (or centimeters) }\end{array}$ & $\begin{array}{l}\text { Formula: } \\
\text { weight }(\mathrm{kg}) \quad / \text { [height }(\mathrm{m})]^{2} \\
\text { Example: } \\
\text { Weight }=68 \mathrm{~kg} \text {, } \\
\text { Height }=165 \mathrm{~cm}(1.65 \mathrm{~m}) \\
\text { Calculation: } \\
68 \div(1.65)^{2}=24.98\end{array}$ \\
\hline Pounds and inches & $\begin{array}{l}\text { Formula: } \\
\text { weight }(\mathrm{lb}) / \text { [height (in) }]^{2} \times 703 \\
\text { Example: } \\
\text { Weight }=150 \mathrm{lbs} \\
\text { Height }=5^{\prime} 5^{\prime \prime} \quad\left(65^{\prime \prime}\right) \\
\text { Calculation: } \\
{\left[150 \div(65)^{2}\right] \times 703=24.96}\end{array}$ \\
\hline & Table-I \\
\hline
\end{tabular}


For adults 20 years old and above. BMI is interpreted using standard weight status categories that are the same for all ages and for both men and women. For children and teens, on the other hand, the interpretation of BMI is both age- and sex-specific.

The standard weight status categories ranges associated with BMI for adults are shown in the following table.

\begin{tabular}{|c|c|}
\hline BMI & Weight Status \\
\hline Below 18.5 & Underweight \\
\hline $18.5-24.9$ & Normal \\
\hline $25.0-29.9$ & Overweight \\
\hline 30.0 and Above & Obese \\
\hline \multicolumn{2}{|c|}{ Table-ll. } \\
\hline
\end{tabular}

The correlation between the BMl amount and body fat is fairly strong; however the correlation varies by sex, race, and age. These variations include the following examples: ${ }^{3,4}$

At the same BMI, women tend to have more body fat than men.

Highly trained athletes may have a high BMI because of increased muscularity rather than increased body fat.

It is also important to remember that BMI is only one factor related to risk for disease. For assessing someone's likelihood of developing overweight- or obesity-related diseases, the National Heart, Lung, and Blood Institute guidelines recommend to look for two other predictors:

The individual's waist circumference (because abdominal fat is a predictor of risk for obesity-related diseases).
Other risks, the individual has, for diseases and conditions associated with obesity are high blood pressure or physical inactivity.

\section{If your BMI is below 20:}

This indicates a lean BMI, which means you have a low amount of body fat. If you are an athlete, this can be desirable. If you are not an athlete, a lean BMI can indicate that your weight may be too low which may lower your immunity. If your BMI and body weight are low, you should consider gaining weight through good diet and exercise habits, to increase your muscle mass.

\section{If your $\mathrm{BMI}$ is between 20 and 22 :}

This indicates the ideal, healthy amount of body fat, which is associated with living the longest, and the lowest incidence of serious illness. Coincidentally, it seems that this ratio is what many individuals perceive to be the most aesthetically attractive.

\section{If your $\mathrm{BMI}$ is between 22 and 25 :}

This is still considered an acceptable range, and is associated with good health.

\section{If your $\mathrm{BMI}$ is between 25 and 30 :}

You are considered "Hefty" and should find ways to lower your weight, through diet and exercise. You are at increased risk for a variety of illnesses at your present weight.

\section{If your BMII is over 30 :}

This indicates an unhealthy condition, your excess "Prosperity" is putting you at risk for heart disease, diabetes, high blood pressure, gall bladder disease and some cancers. You should lose weight by changing your diet.

\section{MATERIAL AND METHODS STUDY DESIGN \\ Descriptive Cross Sectional Study}




\section{SETTING}

People of Ghulam Mohammadabad and Marzi Pura attending OPD at Independent University Hospital Faisalabad.

\section{DURATION OF STUDY}

Two Months (July 2012 to August 2012)

\section{SAMPLING TECHNIQUE}

Convenient sampling

\section{SAMPLE SIZE}

493 individuals

\section{DATA COLLECTION INSTRUMENTS}

A semi structured questionnaire

\section{DATA COLLECTION PROCEDURE}

The investigator himself collected the information from the sample under study. First of all, an informed consent was obtained from the respondents under study and secrecy of the information was ensured.

\section{DATA ANALYSIS PROCEDURE}

Data was analyzed through SPSS Version 17. Frequency tables were prepared.

\section{RESULTS}

The results of this study showed that $\mathrm{BMI}$ is less than 18.5 in $25.4 \%$ of males as compared to $11.5 \%$ in females which indicates that males are more underweight as compared to females while $19.4 \%$ females are having BMI more than 30 as compared to $13.4 \%$ males meaning thereby that females are always on the higher side of BMI.

As far as the age is concerned it is found that BMI increases with age. BMI above 30 in $17.19 \%$ of individuals with age group $20-40$ and $29.2 \%$ of age group 40-60. After 60 years of age it declines to16.1\% in 60-80 age group.
This study also showed that $22.9 \%$ married persons are having BM above 30 as compared to $6.6 \%$ unmarried.

Per month income of the respondents also showed impact on $\mathrm{BMI}$ as $25 \%$ of the persons belonging to high income group were having $\mathrm{BMl}>30$ as compared to $17.5 \%$ in low income group.

Results also showed that $12.9 \%$ of the respondents belonging to rural area were having BMI less than 18.5 as compared to $16.6 \%$ in urban respondents while $20.3 \%$ of the rural respondents were having BMI more than 30 as compared to $16.2 \%$ in urban respondents meaning there by rural respondents are on higher side in both conditions.

This study also showed that $21.1 \%$ of the smokers having BMl above 30 as compared to $18.3 \%$ non smoker and $7.4 \%$ former smokers meaning there by smokers are on higher side in both condition.

No alcoholic was found in this study.

The results of this study also showed difference of BMI with regard to dietary habits and found BMI above 30 in the respondents having meals more than 3 times/day as compared to $21.3 \%$ among persons eating two meals/day.

The study revealed the effect of physical activity on BMI, 23\% persons having intense physical activity has BMI above 30 while $19.6 \%$ in moderate activity, $16.5 \%$ in light activity and $85 \%$ in sedentary life style.

It is found that $17.6 \%$ of the respondents working less that $10 \mathrm{hrs}$ per day were having BMl above 30 and $20.0 \%$ respondents having working hours more than $10 \mathrm{Hrs}$ were having BMI above 30 .

$18.2 \%$ of respondents sleeping less than $10 \mathrm{hrs} /$ day were having BMl above 30 as compared to $15.4 \%$ in 


\begin{tabular}{|c|c|c|c|c|c|c|}
\hline $\begin{array}{c}\text { BMI } \\
\text { VARIABLES }\end{array}$ & FACTORS & $<18.5$ & $18.5-24.9$ & $18.5-24.9$ & $>30$ & $\begin{array}{c}P \text { - } \\
\text { value }\end{array}$ \\
\hline \multirow{2}{*}{ SEX } & FEMALE & 42 (11.5\%) & $171(46.7 \%)$ & 82 (22.4\%) & 71 (19.4\%) & \multirow{2}{*}{.002} \\
\hline & MALE & 32 (25.4\%) & $51(40.5 \%)$ & $26(20.6 \%)$ & 17 (13.5\%) & \\
\hline \multirow{2}{*}{ MARITAL STATIS } & Married & $30(8.8 \%)$ & $138(40.6 \%)$ & $94(27.6 \%)$ & 76 (22.9\%) & \multirow{2}{*}{0.000} \\
\hline & Single & 44 (28.9\%) & 84 (55.3\%) & $14(9.2 \%)$ & $10(6.6 \%)$ & \\
\hline \multirow{3}{*}{ SALARY } & $<10000$ & 38 (12.9\%) & $134(45.4 \%)$ & 72 (24.4\%) & $51(17.3 \%$ & \multirow{3}{*}{0.437} \\
\hline & $10000-30000$ & 32 (18.9\%() & 77 (45.6\%) & $30(17.8 \%)$ & $30(17.8 \%)$ & \\
\hline & $>30000$ & $4(14.3 \%)$ & $11(29.3 \%)$ & $6(21.4 \%)$ & $7(25.0 \%)$ & \\
\hline \multirow[b]{2}{*}{ LOCATION } & RURAL & 26 (12.9\%) & 87 (43.1\%) & 48 (23.8\%) & $41(20.3 \%)$ & \multirow{2}{*}{0.389} \\
\hline & URBAN & 48 (16.6\%) & $135(46.6 \%)$ & $60(20.7 \%)$ & 47 (16.2\%) & \\
\hline \multirow{4}{*}{ AGE GROUP } & $<20$ & 35 (32.7\%) & 57 (53.3\%) & $10(9.3 \%)$ & $5(4.7 \%)$ & \multirow{4}{*}{0.000} \\
\hline & $20-40$ & $25(11.2 \%)$ & $104(46.4 \%)$ & 55 (24.6\%) & 40 (17.19\%) & \\
\hline & $40-60$ & $13(10.0 \%)$ & $43(33.1 \%)$ & $36(27.7 \%)$ & 38 (29.2\%) & \\
\hline & $60-80$ & $1(3.2 \%)$ & $18(58.1 \%)$ & $7(22.6 \%)$ & $5(16.1 \%)$ & \\
\hline
\end{tabular}

Table-III. Sociodemographic factors and BMI

\begin{tabular}{|c|c|c|c|c|c|c|}
\hline VARIABLES & FACTORS & $<18.5$ & $18.5-24.9$ & $18.5-24.9$ & $>30$ & $\mathrm{P}$-value \\
\hline \multirow{3}{*}{ DIABETIC STATUS } & IDDM & $9(14.5 \%)$ & $\begin{array}{c}25 \\
(40.3 \%)\end{array}$ & $\begin{array}{c}16 \\
(25.8 \%)\end{array}$ & 12 (19.4\%) & \multirow{3}{*}{0.662} \\
\hline & IMPAIRED & $6(18.8 \%)$ & $\begin{array}{c}16 \\
(50.0 \%)\end{array}$ & $8(25.0 \%)$ & $2(6.3 \%)$ & \\
\hline & NIDDM & $\begin{array}{c}59 \\
(14.8 \%)\end{array}$ & $\begin{array}{c}181 \\
(45.5 \%)\end{array}$ & $\begin{array}{c}34 \\
(21.1 \%)\end{array}$ & 74 (18.6\%) & \\
\hline \multirow{2}{*}{ GENETIC } & OBESE & $9(15.5 \%)$ & $\begin{array}{c}22 \\
(37.5 \%)\end{array}$ & $\begin{array}{c}14 \\
(24.1 \%)\end{array}$ & $13(22.4 \%)$ & \multirow{2}{*}{0.646} \\
\hline & NON-OBESE & $\begin{array}{c}65 \\
(15.0 \%)\end{array}$ & $\begin{array}{c}200 \\
(46.1 \%)\end{array}$ & $\begin{array}{c}94 \\
(21.7 \%)\end{array}$ & 75 (17.3\%) & \\
\hline
\end{tabular}




\begin{tabular}{|c|c|c|c|c|c|c|}
\hline VARIABLES & & $<18.5$ & $18.5-24.9$ & $18.5-24.9$ & $>\mathbf{3 0}$ & $\begin{array}{l}P \text { - } \\
\text { value }\end{array}$ \\
\hline \multirow{3}{*}{ SMOKING } & $\begin{array}{l}\text { FORMER } \\
\text { SMOKER }\end{array}$ & $4(14.8 \%)$ & $10(37.0 \%)$ & $11(40.7 \%)$ & $2(7.4 \%)$ & \multirow{3}{*}{0.139} \\
\hline & NON-SMOKER & $\begin{array}{c}67 \\
(15.7 \%)\end{array}$ & $196(45.9 \%)$ & $86(20.1 \%)$ & $76(18.3 \%)$ & \\
\hline & SMOKER & $3(7.9 \%)$ & $16(42.1 \%)$ & $11(28.9 \%)$ & $8(21.1 \%)$ & \\
\hline \multirow{2}{*}{ ALCOHIL } & NO & $\begin{array}{c}74 \\
(15.2 \%)\end{array}$ & $218(44.9 \%)$ & $106(21.8 \%)$ & $88(18.1 \%)$ & \multirow{2}{*}{0.394} \\
\hline & YES & $0(0 \%)$ & $4(66.7 \%)$ & $2(33.3 \%)$ & $0(0 \%)$ & \\
\hline \multirow{3}{*}{ DIETARY HABITS } & $>3$ MEALS ADAY & $7(14.9 \%)$ & $18(38.3 \%)$ & $7(14.9 \%)$ & $15(31.9 \%)$ & \multirow{3}{*}{0.000} \\
\hline & 2 MEALS A DAY & $\begin{array}{c}23 \\
(14.8 \%)\end{array}$ & $63(40.6 \%)$ & $36(23.2 \%)$ & $33(21.3 \%)$ & \\
\hline & 3 MEALS A DAY & $\begin{array}{c}44 \\
(15.2 \%)\end{array}$ & $141(48.6 \%)$ & $65(22.4 \%)$ & $40(13.8 \%)$ & \\
\hline \multirow{4}{*}{ PHYCICAL ACTIVITY } & SEDENTARY & $\begin{array}{c}13 \\
(18.3 \%)\end{array}$ & $34(47.9 \%)$ & $18(25.4 \%)$ & $6(8.5 \%)$ & \multirow{4}{*}{0.463} \\
\hline & LIGHT & $\begin{array}{c}26 \\
(14.8 \%)\end{array}$ & $81(46.0 \% 0$ & $40(22.7 \%)$ & $29(16.5 \%)$ & \\
\hline & MODERATE & $\begin{array}{c}16 \\
(16.5 \%)\end{array}$ & $40(41.2)$ & $22(22.7 \%)$ & $19(19.6 \%)$ & \\
\hline & INTENSIVE & $\begin{array}{c}19 \\
(12.8 \%)\end{array}$ & $67(45.3 \%)$ & $28(18.9 \%)$ & $34(23.0 \%)$ & \\
\hline \multirow{2}{*}{ WORKING HOURS } & $<10$ & $\begin{array}{c}64 \\
(14.8 \%)\end{array}$ & $198(45.8 \%)$ & $94(21.8 \%)$ & $76(17.6 \%)$ & \multirow{2}{*}{0.862} \\
\hline & $>10$ & $\begin{array}{c}10 \\
(16.7 \%)\end{array}$ & $24(40.0 \%)$ & $14(23.3 \%)$ & $12(20.0 \%)$ & \\
\hline \multirow{2}{*}{ SLEEPING HOURS } & $<10$ & $\begin{array}{c}61 \\
(13.9 \%)\end{array}$ & $196(44.5 \%)$ & $103(23.4 \%)$ & $80(18.2 \%)$ & \multirow{2}{*}{0.039} \\
\hline & $>10$ & $\begin{array}{c}13 \\
(25.0 \%)\end{array}$ & $26(50.0 \%)$ & $5(9.6 \%)$ & $8(15.4 \%)$ & \\
\hline
\end{tabular}

\section{Table-V. Life style and BMI}

\begin{tabular}{|c|r|c|c|c|c|c|}
\hline \multirow{2}{*}{ FATHER } & OBESE & $9(15.5 \%)$ & $\begin{array}{c}22 \\
(37.5 \%)\end{array}$ & $\begin{array}{c}14 \\
(24.1 \%)\end{array}$ & $\begin{array}{c}13 \\
(22.4 \%)\end{array}$ & \multirow{2}{*}{0.646} \\
\cline { 2 - 6 } & NON-OBESE & $\begin{array}{c}65 \\
(15.0 \%)\end{array}$ & $\begin{array}{c}200 \\
(46.1 \%)\end{array}$ & $\begin{array}{c}94 \\
(21.7 \%)\end{array}$ & $\begin{array}{c}75 \\
(17.3 \%)\end{array}$ & \\
\hline \multirow{2}{*}{ MOTHER } & OBESE & $\begin{array}{c}65 \\
(14.9 \%)\end{array}$ & $\begin{array}{c}192 \\
(44.1 \%)\end{array}$ & $\begin{array}{c}97 \\
(22.3 \%)\end{array}$ & $\begin{array}{c}81 \\
(18.6 \%)\end{array}$ & \multirow{2}{*}{0.538} \\
\cline { 2 - 5 } & NON-OBESE & $9(15.8 \%)$ & $\begin{array}{c}30 \\
(52.6 \%)\end{array}$ & $\begin{array}{c}11 \\
(19.3 \%)\end{array}$ & $7(12.3 \%)$ & \\
\hline
\end{tabular}

Table-VI. Family History of Obesity and BMI 
persons sleeping more than $10 \mathrm{hrs}$ per day.

The results of this study showed that $25.8 \%$ diabetics were having 18.5 - 24.0 BMI while $21.1 \%$. in non diabetics. Similarly the $19.4 \%$ diabetics were obese (BMI > 30) as compared to $18.6 \%$ non diabetics.

Results of this study also showed that $22.4 \%$ of respondents were having history of obesity in their parents.

\section{DISCUSSION}

The results of this study showed that males are more underweight as compared to females so that females are always on the higher side of BMI. In a questionnaire survey conducted by BMC Public Health in 2007 on body mass index, physical activity, and dietary behaviors among members of an urban community fitness center also found that females had lower BMI as compared to the males ${ }^{7}$. There have been numerous large population surveys that measured Body mass index using the median BMI values, which are somewhat representative of "average" people.

These studies always showed that median men have higher BMI values than median women. But the "gap" between men and women's median BMI changes with age because fatness generally increases with age, to a greater extent in women than men.

So for as the age is concerned it is found that BMI increases with age and declines after 60 years of age to $16.1 \%$ which is also proved by another study conducted to assess the association between BMI, Blood Pressure, and Age among Tangkhul Naga Tribal Males of Northeast India in which maximum value for mean BMI was $22.3 \mathrm{~kg} / \mathrm{m}^{2}$, among 40-49 yr age group and declined thereafter with the mean value for BMI of all the age groups was found to be $20.9 \mathrm{~kg} / \mathrm{m}^{2^{6}}$.

This study also showed that $22.9 \%$ married persons were having BMI above 30 as compared to $6.6 \%$ unmarried. This also examined the association between different marital transitions and changes in body mass index (BMI) and body weight in a systematic literature search which was conducted for peer-reviewed articles published between January 1990 and December 2011 found that transitions into marriage were associated with weight gain, whereas transitions out of marriage were associated with weight loss. No major differences were observed between genders or across specific marital transition states $^{17}$.

Per month income of the respondents also showed impact on $\mathrm{BMI}$ as $25 \%$ of the persons belonging to higher income group were having BMI > 30 as compared to $17.5 \%$ in low income group. One of the common myths that exists is that all or virtually all lowincome people are far more likely to be obese. A significant difference in father's BMl was found between middle, low and high-income groups: $10.5 \%$ of fathers in middle-low-income municipalities were obese, compared with $3.8 \%$ in high-income areas. However, middle-low-income children were not isolated and were surrounded by a wider social network than high-income children (80.4\% vs $69 \%$ had more than three friends.

Significant differences were found in the distribution of obesogenic behaviours between middle-low-and high-income municipalities, suggesting that social factors as well as the physical environment should be considered in the development of health policies and interventions to reduce childhood obesity ${ }^{18}$.

Results also showed that $12.9 \%$ of the respondents belonging to rural area were having BMI less than 18.5 as compared to $16.6 \%$ in urban respondents while $20.3 \%$ of the rural respondents were having BMI more than 30 as compared to $16.2 \%$ in urban respondents. It was further augmented by another study which found obesity prevalence $39.6 \%$ among rural adults 
compared to $33.4 \%$ among urban adults. Obesity is markedly higher among adults from rural versus urban areas of the United States, with estimates that are much higher than the rates suggested by studies with self-reported data. Obesity deserves greater attention in rural America ${ }^{16}$.

This study also showed that $21.1 \%$ of the smokers have BMI above 30 as compared to $18.3 \%$ in non smoker and $7.4 \%$ informer smokers. It is different from another community-based study in the population in Delhi, that showed smoking negatively associated with BMI. The median BMI was higher in non-smokers as compared to smokers. The proportion of overweight and obese subjects was greater among non-smokers as compared to smokers while underweight subjects were in higher proportions among smokers as compared to nonsmokers ${ }^{13}$.

The results of this study also showed difference of BMI with regard to dietary habits and found $\mathrm{BMI}$ above 30 in the respondents having meals more than 3 times/day as compared to $21.3 \%$ among persons eating two meals/day. Another study was conducted to assess the associations and impact of increased meal frequency, physical activity and 'skipping' breakfast on obesity levels in a sample of urban adolescents, aged 13-17 years old, from Porto, Portugal and found that the proportion of overweight/obese girls and boys that consumed fewer than three meals was significantly higher than those reported from normalweight counterparts indicating that increased meal frequency may have a beneficial effect on a reduced $\mathrm{BMI}^{14}$.

Eating three or fewer meals per day was also associated with increased likelihood of general and central obesity in men when adjusting for total energy intake, lifestyle and dietary factors. However, results did not reach statistical significance among women. The present study suggests that a high daily eating frequency is associated with a healthy lifestyle and dietary pattern in both men and women, and a reduced likelihood of general and central obesity in men. There is a need for prospective studies investigating the association between eating frequency, diet and body composition $^{15}$.

Most studies indicate an inverse relationship between physical activity and body mass index (BMI). However, the impact of obesity on this relationship is still unclear. On the other hand physical activity also inversely associated with age and education. This study revealed the inverse effect of physical activity on BMI as $23 \%$ person having intense physical activity has BMI above 30 while 19.6\% in moderate activity, $16.5 \%$ in light activity and $8.5 \%$ in sedentary life style which is different from another study showing that the weak association between physical activity and BMI in non-obese individuals but significantly associated with physical activity in obese individuals. Longitudinal studies are needed to tease out the direction of association between PA and BMI across BMI categories, as the cross-sectional associations seem to be dependent on obesity status ${ }^{10}$.

The effect of working hours on BMI were also studied and found that the respondents working more than 10 hours have more BMI as compared to those respondents working less that $10 \mathrm{hrs}$ per day which indicate a positive association between hours of working and BMI.

A cross-sectional population-based survey was conducted among working Australians in the state of Victoria for psychosocial and other working conditions in relation to body mass index in a representative sample of Australian workers and found among men and women differing patterns of both exposures to psychosocial working conditions and associations with BMI. Among men, working long hours was positively associated with higher $\mathrm{BMI}$ and this association was partly independent of job stress. Among men physical demand was negatively associated with $\mathrm{BMI}$ and this association was 
independent of job stress. However these limitations must be taken into account. First, the cross-sectional design of our study cannot support causal inferences between occupational factors and BMI ${ }^{12}$.

The effect of sleeping on the BMI was also taken into account and found that respondents sleeping less than $10 \mathrm{hrs} /$ day were having BMI above 30 as compared to those sleeping more than $10 \mathrm{hrs}$ per day. No matter what other factors are concerned, sleeping time seems to be the most important factor to affect BMI because this result was further augmented by a study showing that people who sleep less than 5 or more than 9 hours will have an average BMI greater than those who sleep for 6-9 hours. As we see that age and eating habit will affect the BMI, sleeping time will affect the BMI too. Best sleeping time is 6-9 hours. Avoid sleeping too little (less than 5 hours) or too much (above 9 hours). It will lead to a high Body Mass Index and also many other diseases or even lead to death ${ }^{11}$.

The effect of diabetes mellitus on BMI was also studied in this study and found an increase of $4 \%$ of $\mathrm{BMI}$ in the respondents having diabetics mellitus as compared to non-diabetics. Similarly $19.4 \%$ diabetics were obese (BMI >30) as compared to $18.6 \%$ non diabetics. The relationship of body mass index to diabetes mellitus, hypertension and dyslipidaemia were also studied with the comparison of the data from two national surveys SHIELD and NHANES in 2007. Both surveys showed that an increase in BMI is generally associated with a significant increase in prevalence of diabetes mellitus, hypertension and dyslipidaemia. The prevalence of diabetes mellitus and hypertension increased in an observable, linear fashion as BMl levels increased. The prevalence of diabetes mellitus was highest among morbidly obese individuals (BMI $\geq 40$ ), with rates of 25\% (SHIELD) and $27 \%$ (NHANES) ${ }^{8}$.

Results of this study also showed that $22.4 \%$ of respondents were having history of obesity in their parents.

\section{Copyright(C) 25 0ct, 2013}

\section{REFERRENCES}

1. Centers for Disease Control and Prevention 1600 Clifton Rd. Atlanta, GA 30333 , USA 800-CDC-INFO (800-232-4636) TTY: (888) 232-6348 -cdcinfo@cdc.gov.

2. Chhabra P,Chhabra S K. Effect of smoking on body mass index: a community-based study. National Journal of Community Medicine Vol 2 Issue 3 Oct-Dec 2011

3. Luo M,Zhang C. Non-Linear Relationship between Body Mass Index and Labor Market Outcomes: New Evidence from China. J occupational health ;2010:52.66-73.

4. Bays HE, Chapman R. H., Grandy V. The relationship of body mass index to diabetes mellitus, hypertension and dyslipidaemia: comparison of data from two national surveys. The Authors AstraZeneca Pharmaceuticals LP Int J Clin Pract, May 2007, 61, 5, 737-747.

5. M. Arantxa Colchero Benjamin Caballerob, David Bishaia The effect of income and occupation on body mass index among women in the Cebu Longitudinal Health and Nutrition Surveys (1983-2002) ${ }^{a}$ Department of Health Eco Social Science \& Medicine Volume 66, Issue 9, May 2008, Pages 1967-1978.

6. Mungreiphy NK, Kapoor S, and Sinha R. Association between BMI, Blood Pressure, and Age: Study among Tangkhul Naga Tribal Males of Northeast India. Journal of Anthropology Volume 2011 (2011), Article ID 748147, 6 pages doi:10.1155/2011/74 8147.

7. Kaphingst KA, Bennett GG, Sorensen G, Kaphingst $\mathrm{KM}$, Neil AEO and Mclnnis K. Body mass index, physical activity, and dietary behaviors among members of an urban community fitness center: a questionnaire survey BMC Public Health 2007, 7:181 doi:10.1186/1471-2458-7-181 Bays HE, Chapman R. $H$., Grandy V. The relationship of body mass index to diabetes mellitus,hypertension and dyslipidaemia: comparison of data from two national surveys. The Authors AstraZeneca Pharmaceuticals LP Int J Clin Pract, May 2007, 61, 5, 737-747. 
10. Hemmingsson $E$, Ekelund $U$. Is the association between physical activity and body mass index obesity dependent? Int J Obes (Lond). 2007 Apr;31(4):663-8. Epub 2006 Sep 5.

11. Chan Long Tin,Chan Tak Lai,Chau Hau Chi, Leung Ka Wai,Lam Ya. The effect of sleeping time on BMI Cheung Chuk Shan College.

12. Aleck S 0stry1 ${ }^{*}$, Samia Radi2 34 , Amber M Louie1 and Anthony D LaMontagne4 Psychosocial and other working conditions in relation to body mass index in a representative sample of Australian workers BMC Public Health 2006, 6:53 doi: 10.1186/1471-2458-6-53.

13. Chhabra P, Chhabra S K. Effect of smoking on body mass index: acommunity-based study. National Journal of Community Medicine Vol 2 Issue 3 OctDec 2011.

14. Relationships between physical activity, obesity and meal frequency in adolescents 2008, Vol. 35, No. 1 , Pages 1-10 (doi:10.1080/03014460701779617).

15. Holmbäck I, Ericson U ${ }^{1}$, Gullberg B and Wirfält E. A high eating frequency is associated with an overall healthy lifestyle in middle-aged men and women and reduced likelihood of general and central obesity in men. Br J Nutr. 2010 Oct;104(7): 106573.doi: 0.1017/S00071145100017 53. Epub 2010 May 26.

16. Christie A. Befort $\mathrm{PhD}^{1}$, Niaman Nazir MD ${ }^{1}$,Michael G. Perri $\mathrm{PhD}^{2}$. Prevalence of Obesity Among Adults From Rural and Urban Areas of the United States: Findings From NHANES (2005-2008). The Journal of Rural Health Volume 28,Issue 4, pages 392-397, Autumn 2012 Article first published online: 31 MAY 2012 D0I: 10.1111/j.1748-0361.2012.00411.

17. Lauren Dinour,1 MayMay Leung,2 Gina Tripicchio,2 Sahar Khan,2 and Ming-Chin Yeh2. The Association between Marital Transitions, BodyMass Index,andWeight: A Review of the Literature Hindawi Publishing Corporation Journal of Obesity Volume 2012, Article ID 294974, 16 pages doi:10. $1155 / 2012 / 294974$

18. Gregori D, Foltran F, Ghidina M, Zobec F, Berchialla P. Familial environment in high- and middle-lowincome municipalities: a survey in Italy to understand the distribution of potentially obesogenic factors. Public Health. 2012 Sep;126(9): 731-9. doi: 10.1016/j.puhe.2012.05.010. Epub 2012 Jul 11.
AUTHOR(S):

1. DR. ABDUL SATTAR

Associate Professor

Department of Community Medicine Independent Medical College, Faisalabad.

2. DR. SHAHBAZ BAIG

Assistant Professor

Department of Community Medicine Independent Medical College, Faisalabad.

3. DR. NAVEED UR REHMAN

Assistant Professor

Department of Medicine

Independent Medical College, Faisalabad.
4. Dr. Muhammad Badar Bashir

Professor

Department of Medicine

Independent Medical College, Faisalabad.

Correspondence Address:

Dr. Shahbaz Baig

Department of Community Medicine

Independent Medical College, Faisalabad.

talha_shahbaz557@yahoo.com

Article received on: 20/06/2013

Accepted for Publication: 25/10/2013

Received after proof reading: 03/12/2013 